Кретов В.В., Севрюгин В.Е.

\title{
О НЕОБХОДИМОСТИ УСТАНОВЛЕНИЯ АДМИНИСТРАТИВНОЙ ОТВЕТСТВЕННОСТИ ЗА ПРАВОНАРУШЕНИЯ В ОБЛАСТИ ДОРОЖНОГО ХОЗЯЙСТВА РОССИЙСКОЙ ФЕДЕРАЦИИ
}

\begin{abstract}
Аннотация: В статье анализируются нормы федерального закона "Об автомобильных дорогах и дорожной деятельности» и Кодекса Российской Федерации «Об административных правонарушениях» в части, касающейся установления административной ответственности как пользователей автомобильных дорог (физических и юридических лиц), так и должностных лиц органов управления дорожной отраслью за допущенные нарушения по ремонту, содержанию автомобильных дорог и их сохранность. Предложены меры по совершенствованию законодательства об административных правонарушениях, включающие ужесточение ответственности и введение дополнительной главы в Особенную часть КоАП РФ. В ходе исследования были использованы такие методы исследования как системный, сравнительно-правовой и формально-логический. Совершенствование Кодекса Российской Федерации “Об административных правонарушениях», а также Федерального закона "Об автомобильных дорогах и дорожной деятельности..» № 257-Ф3 от 8.11.2007, путем включения в них новых норм об ответственности в области автомобильных дорог и дорожной деятельности, позволит не только оптимизировать систему ответственности пользователей дорог и организаций, осуществляющих эксплуатацию дорог, но и привести в систему ответственность органов управления дорожным хозяйством, а также их руководителей.
\end{abstract}

Ключевые слова: дороги, дорожная деятельность, адвминистративна ответственность, дорожное законодательство, административные правонарушения, пользователи дорог, должностные лица, административный итраф, физические лиза, юридические лица.

Review: The article analyzes the provisions of the Federal law "On automobile roads and road activities" and Code of the Russian Federation "On administrative offences" regarding imposition of administrative responsibility for both road users (individuals and legal entities) and officers of the traffic control sector for violations in repair, roads maintenance and safety. The authors propose the measures for improvement of the legislation on administrative offences, including toughening of responsibility and introduction of additional chapter in the Special part of the administrative code. The authors use the system, the comparative legal and the formal logical methods. The improvement of the Code Of The Russian Federation "On administrative offences" and the Federal law "On automobile roads and road activities.." No. 257-FL dated 8.11.2007 through the inclusion of new rules on liability in the sphere of roads and road-related activities, will allow not only to improve the responsibility system of road users and organizations involved in the operation of roads, but also to codify the responsibilities of road management, as well as their managers.

Keywords: officials, road users, administrative offences, road legislation, administrative responsibility, road activities, roads, administrative fine, individuals, legal entities.

C овременное состояние сети автомобильных дорог и ее корреляция с состоянием безопасности дорожного движения в России в последнее десятилетие имеет стойкую тенденцию к ухудшению. Это вызвано следующими факторами: во-первых, постоянным ростом числа транспортных средств; во-вторых, неразвитостью дорожной инфраструктуры, ее отставанием по сравнению с резким ростом числа автотранспортных средств (при наличном состоянии автодорог с твердым покрытием и подобных темпах их строительства и введения в эксплуатацию, мы отстаем от развитых стран Европы, США, Канады, Китая, Японии примерно на 200 лет); в-третьих, переадресацией пассажирских потоков с железнодорожного и водного транспорта на автомобильный транспорт; в-четвертых, расширением международных автомобильных перевозок и использованием сети автодорог России в качестве транзитных коридоров; в-четвертых, постоянным реформированием органов, осуществляющих управление дорожной отраслью и органов по надзору в области безопасности дорожного движения: в-пятых, несовершенством действующего дорожного законодательства, обеспечивающего выполнение лишь $30 \%$ объема необходимых нормативно-восстановительных и экс- 
плуатационных работ [1], что ведет к деградации уже существующей сети автодорог и возможности их обвального разрушения; в-шестых, чрезвычайно низкими темпами строительства современных новых автомобильных дорог (2-3 тысяч км в год) при потребностях не менее 20-30 тысяч км в год [2].

В настоящее время для эффективного динамичного развития экономики страны необходимо обеспечить строительство новых федеральных автомобильных дорог протяженностью не менее одного миллиона километров [3] (к уже существующим 544 тыс. км дорог, без учета муниципальных дорог) и реконструировать $80 \%$ действующей сети автомобильных дорог общего пользования.

Как показывает анализ темпов развития экономики, большинство развиты стран мира (Германия, США, Япония, Китай и др.), они осуществляли выход из сложных экономических ситуаций именно за счет активизации развития автодорожных сетей. В современных условиях не требует доказательства тот факт, что именно недостаточная развитость и неудовлетворительное состояние сети автомобильных дорог стали существенным тормозом в развитии экономики России.

Проведенный комплексный анализ существующей системы нормативно-правового регулирования дорожного хозяйства и автодорожной инфраструктуры позволяют выявить наиболее характерные недостатки. К их числу, как представляется, можно отнести следующие:

1) действующая нормативная правовая база не в полной мере регулирует общественные отношения в этой области, характеризуется целым рядом противоречий и нуждается в диверсификации;

2) отсутствует четкое нормативно-правовое закрепление ведения, прав, обязанностей и ответственности субъектов дорожной отрасли управления на всех уровнях;

3) имеются проблемы в нормативном правовом регулировании координации деятельности органов исполнительной власти как на федеральном, так и на региональном и местном уровнях;

4) недостаточно детально определен порядок и объем финансирования развития, совершенствования и эксплуатации дорожной сети страны;

5) слабо регламентированы форма и методы контроля за развитием сети автомобильных дорог страны до уровня, удовлетворяющего спрос пользователей автомобильных дорог, а также сам контроль за органами и организациями, обеспечивающими ее поддержание в состоянии, отвечающем требованиям действующих нормативно-технических документов;

6) практически отсутствуют нормы, стимулирующие увеличение межремонтных и общих сроков службы автодорог (до нормативных и выше нормативных) за счет повышения эффективности управления состоянием дорог и обеспечения их сохранности от противоправных воздействий пользователей (физических и юридических лиц);

7) законодательство об административной ответственности в области дорожного хозяйства, в целом, не обеспечивает в полной мере реализацию главных задач - развития и поддержание дорожной сети страны в нормативном состоянии.

За время действия Федерального закона «Об автомобильных дорогах и дорожной деятельности» от 08 марта 2007 г № 257-Ф3 (далее Закон) ситуация в стране в лучшую сторону не изменилась. Хотя и разработан и введен в действие ряд законодательных актов, в том числе регламентирующих компетенцию органов государственных (исполнительных) органов субъектов Российской Федерации и органов местного самоуправления, но, к сожалению, в принятых законодательных актах вопросы развития дорожной сети и дорожного хозяйства не получили должного нормативного отражения. Отсутствует также и административная ответственность должностных лиц органов исполнительной власти всех уровней за состояние дорог, качество их ремонта и содержания.

Действующее федеральное законодательство об автомобильных дорогах и дорожной деятельности в основном носит диспозитивный характер. Фактически все статьи, содержащиеся в Ф3 «0б автомобильных дорогах и дорожной деятельности...» закрепляют диспозитивные нормы, санкции в структуре которых отсутствуют. Ответственности за нарушения в сфере автомобильных дорог и дорожной деятельности посвящена лишь одна, сорок шестая статья закона, носящая отсылочный характер и не учитывающая всей специфики дорожного хозяйства как отрасли.

Происходит это прежде всего потому, что Закон определяет осуществление дорожной деятельности как право государственных органов исполнительной власти, а отнюдь не обязанность, при том, что осуществление дорожной деятельности является основной функцией, определяющей 
смысл функционирования дорожного хозяйства. В результате, при фактическом допущении государственным органом нарушений в осуществлении дорожной деятельности (необеспечение объективной информацией о состоянии дорог, отсутствие обоснованного планирования, невыполнение нормативных требований при ремонте и содержании дорог и др.) ежегодно в дорожно-транспортных происшествиях получают увечья и гибнут тысячи людей, портятся перевозимые грузы, приходит в негодность автотранспорт. При этом, никто не несет юридической (правовой) ответственности за неудовлетворительное состояние дорог, из-за которого гибнут люди и терпят ущерб пользователи.

Сложившаяся система правовых норм, регулирующая взаимоотношения в сфере дорожного хозяйства, не позволяет обеспечить эффективный контроль за деятельностью государственных органов, осуществляющих управление дорожным хозяйством. Отсутствие в Законе важных понятий, являющихся определяющими в сфере дорожного хозяйства, в том числе и понятия самого «дорожного хозяйства», позволяет говорить о том, что органы управления, осуществляющие свою деятельность в сфере дорожного хозяйства, и в первую очередь по развитию и содержанию сети автомобильных дорог, не несут за качество своей работы никакой ответственности. В стране как отсутствовали, так и отсутствуют независимые контрольные органы по оценке реального состояния дорог и критерии оценки дорожной деятельности, и главное - отсутствует понимание того, что необходимо сделать для достижения главной цели дорожного хозяйства и в каких объемах. Имеющиеся отраслевые надзорные органы действуют по формальному принципу и не в состоянии привлечь к административно-правовой ответственности лиц, наделенных полномочиями по осуществлению ремонта и содержания дорог, не способных привести существующую дорожную сеть в состояние, отвечающее требованиям действующих норм, не говоря уже о совершенствовании дорожной сети и строительстве новых дорог.

В связи с этим, одной из первоочередных задач развития системы административно-правовой ответственности в сфере дорожного хозяйства, должна стать разработка правовых норм, закрепляющих юридическую (правовую) ответственность органов исполнительной власти (органов управления дорожным хозяйством) за профессиональное выполнение возложенных на них полномочий по проектированию, строительству, ремонту и содержанию сети автомобильных дорог.
Одним из первых шагов в направлении улучшению ситуации в области повышения юридической ответственности органов управления дорожным хозяйством за развитие и состояние дорожной сети, может стать корректировка и конкретизация основных полномочий, которыми эти органы наделены. В настоящее время, при существующих общих, размытых полномочиях, закрепленных в действующем законодательстве, не может идти и речи об ответственности за их профессиональную реализацию. В связи с отсутствием в действующих положениях анализируемого закона конкретики, фундаментом для повышения эффективности управления дорожным хозяйством может стать система персональной ответственности первых руководителей государственных органов управления дорожным хозяйством за обязательное исполнение ряда основных полномочий, возложенных на них законом.

К таким полномочиям, в рамках одиннадцатой статьи упомянутого Закона предлагается отнести:

1. Полномочия по определению основных направлений государственной политики в области использования автомобильных дорог и осуществления дорожной деятельности (ст. 11.1). Эти полномочия в первую очередь должны быть направлены на достижение главной цели дорожного хозяйства страны -удовлетворение спроса пользователей дорогами на безопасное, бесперебойное, с расчетными скоростями движение автотранспорта по дорогам общего пользования. Такая цель предопределяет и основные направления государственной политики, в первую очередь подразумевающие активное развитие сети дорог страны (необходимо построить около одного миллиона километров новых дорог) и приведение действующей сети автомобильных дорог в состояние, отвечающее требованиям действующих нормативно-технических документов, поскольку более половины имеющихся дорог не отвечают требованиям этих норм. Как показал сравнительно-правовой анализ действующих правовых актов, такие направления в сфере дорожной деятельности государственными органами управления дорожным хозяйством не определены. Поскольку нет четко сформулированной государственной политики в указанных направлениях, то нет и улучшения состояния дорожной сети, не обеспечивается активное ее развитие и приведение в нормативное состояние. Как следствие, принимаемые целевые программы по развитию и совершенствованию дорожной сети страны во многих случаях не выполняются даже 
при абсолютной минимизации планируемых в них мероприятий.

Органы исполнительной власти, наделенные действующим Законом такими важными полномочиями, по определению государственной политики в сфере осуществления дорожной деятельности, и не определяющие ее, а также не обеспечивающие ее реализацию на необходимом профессиональном уровне, должны считаться нарушителями закона и нести юридическую ответственность соразмерную допущенному правонарушению.

2. Важные полномочия государственных органов, определяющих необходимость установления общих требований к осуществлению контроля за обеспечением сохранности автомобильных дорог и порядку осуществления данного контроля закреплены в статьях 11.2 и 11.3 упомянутого закона. Предпринятый анализ качества реализации этих полномочий показывает, что они также не реализованы на необходимом профессиональном уровне по разным причинам, в том числе по причине отсутствия в законе четкого понятия такого важного термина как «обеспечение сохранности автомобильных дорог». Если исходить из анализа положений, закрепленных в статьях 28 и 29 Закона, то под обеспечением сохранности дорог следует понимать предотвращение отрицательных воздействий на дороги пользователей и иных юридических и физических лиц. Борьбой с этими отрицательными воздействиями (то есть правонарушениями) на практике занимаются органы исполнительной власти при осуществлении дорожной деятельности. Однако исследования, проведенные российскими и зарубежными учеными [4] показывают, что фактически наибольший ущерб дорогам наносится невыполнением или ненадлежащим выполнением регламентированных работ по их содержанию и ремонту.

При ненадлежащем или несвоевременном выполнении работ по ремонту и содержанию дорог, происходит ускоренное их разрушение, на устранение которого расход финансовых средств увеличивается в разы. При этом значительный ущерб причиняется и пользователям дорог (для удовлетворения потребностей которых и строятся автомобильные дороги). Исследования Всемирного банка реконструкции и развития [5] показывают, что один доллар, недовложенный в содержание и ремонт дороги приносит пользователям три доллара убытков в виде срывов сроков поставки, ускоренного износа транспорта, порчи перевозимых грузов и т.д.
Органы государственной власти и их руководители, наделенные конкретными полномочиями в области содержания дорог и обеспечения их сохранности, и не реализующие данные полномочия на необходимом профессиональном уровне, что подтверждается несвоевременным и некачественным выполнением требуемых работ по ремонту и содержанию дорог, обязаны нести административную ответственность, адекватную величине нанесенного ущерба.

3. Одной из важнейших в Законе является статья 11.10 определяющая полномочия органов исполнительной власти по осуществлению дорожной деятельности в отношении автомобильных дорог. Исходя из смысла статьи 3.6 закона, «под дорожной деятельностью следует понимать деятельность по проектированию, строительству, реконструкции, капитальному ремонту, ремонту и содержанию автомобильных дорог». Таким образом, органы исполнительной власти наделены полномочиями по выполнению перечисленных видов работ.

Полномочия являются узаконенным правом осуществления деятельности органами исполнительной власти, в соответствии с которыми они имеют право заниматься всеми указанными видами дорожной деятельности, от проектирования до содержания дороги.

Однако, содержание дорог не может быть эффективным и надежным при наличии у органов исполнительной власти, занимающихся этим видом работ, только лишь прав при полном отсутствии обязанностей. Как известно, содержание автомобильных дорог требует выполнения целого комплекса обязательных работ, невыполнение которых, помимо экономических потерь, приводит и к тяжелым, необратимым последствиям - гибели людей на дорогах. Обращает на себя внимание и то, что одной из основных причин участившихся случаев аварий, дорожно-транспортных происшествий и перерывов в движении на важнейших российских дорогах, является отсутствие соответствующих обязанностей и, как следствие, ответственности за качественное и своевременное выполнение работ у органов управления и власти, осуществляющих этот вид дорожной деятельности.

Названные выше причины и условия, позволяют говорить о необходимости установления юридической (правовой) ответственности органов исполнительной власти за качественное и своевременное исполнение возложенных на них полномочий по осуществлению дорожной деятельности. 
При этом, возложенная действующим законодательством обязанность исполнения полномочий, предоставленных органам исполнительной власти в сфере дорожной деятельности, предлагается закрепить в конкретных нормах Федерального закона «Об автомобильных дорогах и дорожной деятельности...», путем внесения следующим измененным и дополнений:

11.1 определение основных направлений государственной политики в области использования автомобильных дорог и осуществления дорожной деятельности с конкретизацией целей по развитию, совершенствованию и приведению в нормативное состояние сети автодорог общего пользования;

11.2 установление общих требований к осуществлению контроля и осуществление контроля в ходе обеспечения сохранности дорог от правонарушений, совершаемых государственными органами управления дорогами, пользователями дорогами, эксплуатирующими организациями, а также иными физическими и юридическими лицами;

11.10 осуществление дорожной деятельности с целью реализации основных направлений государственной политики по развитию, совершенствованию сети автомобильных дорог и ее содержанию в состоянии, соответствующем требованиям нормативно-технических документов;

11.17 обеспечение пользователей автомобильными дорогами общего пользования объективной информацией об интересующих их маршрутах передвижения, состоянии дорог в т.ч. о допустимых максимальных безопасных скоростях движения на участках дорог с техническими показателями (ровностью, коэффициентом сцепления и т.д.) ниже нормативных;

11.22 разработка программ стратегических научных исследований в сфере дорожного хозяйства, обеспечивающих:

- повышение эффективности правового обеспечения дорожного хозяйства;

- повышение эффективности управления дорожным хозяйством;

- создание системы адекватного финансирования дорожной деятельности;

- снижение ресурсоемкости дорожного производства, стоимости строительства и эксплуатации автомобильных дорог;

- повышение межремонтных и общих сроков службы автомобильных дорог и дорожных сооружений.

11.23 обеспечение реализации программ стратегических научных исследований в сфере дорожного хозяйства.
Установление в Законе обязанности исполнения органами государственной власти в области использования автодорог и осуществления дорожной деятельности предоставленных им полномочий, предопределяет необходимость включения в Закон норм об ответственности за неисполнение или некачественное исполнение этих полномочий. Что позволит квалифицировать эти деяния как административные правонарушения и привлекать виновных лиц к административной ответственности.

В целях конкретизации и расширения перечня правонарушений в области дорожного хозяйства, предлагается внести изменения и дополнения в отдельные статьи Федерального закона «Об автомобильных дорогах и дорожной деятельности...», изложив их в следующей редакции:

В статью 29, устанавливающую перечень основных запрещенных видов действий для пользователей и иных лиц, включить:

осуществлять движение по автомобильным дорогам на транспортных средствах имеющих элементы конструкций или конструкций перевозимых грузов которые могут нанести повреждения автомобильным дорогам;

п.2 Пользователям дорог и иным осуществляющим использование автомобильных дорог лицам запрещается:

1) загрязнять проезжую часть, обочины, придорожные полосы и полосы отвода автомобильных дорог;

2) использование водоотводных сооружений для сброса или стока вод и других жидкостей;

3) выполнять в границах полос отвода автомобильных дорог, в том числе на проезжей части, обочинах, откосах автомобильных дорог, работы, связанные с применением горючих веществ, а также веществ, которые могут оказать воздействие на уменьшение сцепления колес транспортных средств с дорожным покрытием».

Статью 46, устанавливающую ответственность за нарушения законодательства Российской Федерации об автомобильных дорогах и дорожной деятельности изложить:

п.2 Органы государственной власти, наделенные полномочиями по осуществлению дорожной деятельности, либо должностные лица этих органов несут административную ответственность за несвоевременное или некачественное исполнение возложенных на них полномочий, наносящих ущерб автомобильным дорогам, пользователям дорогами и иным лицам. 
В Кодексе Российской Федерации «Об административных правонарушениях», нет отдельной главы, посвященной правонарушениям в области автомобильных дорог и дорожной деятельности.

В связи с этим, в статье рассмотрены два варианта решения проблемы обеспечения адекватной ответственности за административные правонарушения, совершаемые в области дорожного хозяйства.

Первый вариант предусматривает совершенствование действующего законодательства.

Возможные правонарушения в сфере дорог приведены в двух главах КоАП - одиннадцатой и двенадцатой. В них рассмотрены правонарушения, совершаемые пользователями дорог, дорожными организациями и иными лицами. Конкретные виды таких нарушений и ответственности за их совершение нашли отражение в двух статьях $(11.21,11.22)$ одиннадцатой главы КоАП, посвященной административным правонарушениям на транспорте.

В статье 11.21 определены нарушения правил использования полос отвода и придорожных полос автомобильных дорог. В данной норме правонарушения представлены не в полном объеме. В перечень не включены такие часто встречающиеся нарушения, как:

- съезды автотранспорта на придорожные полосы и движение по ним, что приводит к разрушению ровности поверхности полосы (особенно в сырую погоду), а в дальнейшем к застою воды в образовавшейся колее и в результате - нарушению водоотвода от автомобильной дороги.

- повреждение и замусоривание водоотводных канав, лотков, кюветов и других подобных дорожных сооружений, находящихся на полосах отвода;

- повреждение укреплений откосов насыпей и выемок, конусов, мостов, водопропускных труб и других дорожных сооружений.

Необходимо отметить, что указанные в статье суммы штрафов (особенно для физических и должностных лиц) в большинстве случаев не обеспечивают возмещение причиненного ущерба.

В связи с этим, размеры штрафов предлагается увеличить:

- $\quad$ для физических лиц от десяти до тридцати тысяч рублей;

- для должностных лиц от тридцати до пятидесяти тысяч рублей.

В статье 11.22, определяющей нарушения землепользователями правил охраны автомобильных дорог и дорожных сооружений, вносится предло- жение об ужесточении наказания должностных и юридических лиц. Необходимость увеличения суммы штрафов обусловлена часто встречающимися случаями загрязнения дорог общего пользования автотранспортом, выезжающим с производственных баз и строительных площадок в грязном виде. В связи с этим предлагается ввести следующие размеры штрафов:

- должностным лицам от десяти до пятидесяти тысяч рублей;

сяч рублей.

В главе 12, посвященной административным правонарушениям в области дорожного движения, вопросам обеспечения сохранности автодорог посвящены три статьи. Особенностью правонарушений в области дорожного движения является то, что вред автомобильным дорогам причиняется при нарушении правил дорожного движения и эксплуатации транспортных средств.

Так в статье 12.21.1. КоАП определены нарушения правил, допускаемые при перевозке крупногабаритных и тяжеловесных грузов, совершение которых довольно часто приводит к разрушению и повреждению дорожных конструкций (дорожных одежд искусственных сооружений обстановки дороги и т.д.). по мнению автора, в два пункта этой статьи - 1-й и 3-й также необходимо внести изменения. В пункте 1-ом, определяющем наказание за перевозку крупногабаритных и тяжеловесных грузов без специальных разрешений, предлагается значительно увеличить размеры административного штрафа, возлагаемые на должностных лиц, отвечающих за перевозку : от ста до пятисот тысяч рублей, на юридических лиц - от пятисот тысяч до трех миллионов рублей. Необходимость увеличения сумм штрафов обусловлена тем, что многие перевозчики, в целях экономии средств, осознанно нарушают законодательство и перевозят грузы без разрешений, поскольку сумма штрафа меньше стоимости получения разрешения на перевозку. Часто, последствиями таких нарушений являются разрушенные мосты и поврежденные дороги.

В пункте, определяющем наказание за превышение максимальной массы или нагрузки на ось (при осуществлении перевозки тяжеловесного груза) более чем на $5 \%$ предлагается конкретизировать нарушение и наказание, изложив их в следующей редакции:

Превышение разрешенной максимальной массы:

- $\quad$ до 2 тонн влечет наложение административного штрафа на водителя в размере от полутора 
до двух тысяч рублей; на должностное лицо в размере от десяти до пятнадцати тысяч рублей; на юридическое лицо - в размере от ста до ста пятидесяти тысяч рублей;

- $\quad$ от 2 до 5 тонн влечет наложение административного штрафа на водителя от двух с половиной до десяти тысяч рублей; на должностное лицо - в размере от ста до ста пятидесяти тысяч рублей; на юридическое лицо - в размере от ста пятидесяти до пятисот тысяч рублей;

- $\quad$ более 5 тонн влечет наложение штрафа на водителя в размере от десяти до двадцати тысяч рублей или лишение права управления транспортным средством на срок до 6 месяцев; на должностное лицо - в размере от ста пятидесяти до пятисот тысяч рублей; на юридических лиц - в размере от пятисот тысяч до двух миллионов рублей.

При превышении разрешенной нагрузки на ось:

- $\quad$ до 1 т влечет наложение административного штрафа на водителя в размере от полутора до двух с половиной тысяч рублей; на должностное лицо - в размере от десяти до пятнадцати тысяч рублей; на юридическое лицо - в размере от ста до ста пятидесяти тысяч рублей.

- $\quad$ от 1 т до 3 т - влечет наложение административного штрафа на водителя - от двух с половиной до десяти тысяч рублей; на должностное лицо - в размере от ста до ста пятидесяти тысяч рублей; на юридическое лицо - в размере ста пятидесяти до пятисот тысяч рублей;

- более 3 т - влечет наложение штрафа на водителя в размере от десяти до двадцати тысяч рублей. или лишение права управления транспортным средством на срок до 6 месяцев; на должностное лицо - в размере ста пятидесяти до пятисот тысяч рублей; на юридических лиц - в размере от миллиона до двух миллионов рублей.

При повторном нарушении правил перевозки водитель лишается права управления транспортным средством на 6 месяцев, юридическое лицо, осуществляющее перевозку - лишается лицензии на право перевозки грузов.

Статья 12.33 устанавливает ответственность за повреждение дорог, железнодорожных переездов или других дорожных сооружений, создающих угрозу безопасности дорожного движения. Представляется, что установленный в данной статье административный штраф, должен предъявляться лицам, осуществившим такие разрушения и создавшим помехи в дорожном движении вне зависимости от того, создает это угрозу безопасности дорожного движения или нет. В связи с этим, предлагается следующая формулировка ст. 12.33:

Повреждение дорог, железнодорожных переездов, других дорожных сооружений либо умышленное создание помех в дорожном движении, влечет наложение административного штрафа... И далее по тексту.

Необходимость изменения содержания статьи предопределена тем, что случаев разрушений проезжей части, обочин, обстановки дороги, искусственных сооружений, загрязнения дороги в реальности происходит довольно часто и лица, совершающие данные деяния должны нести соответствующий вид правовой ответственности в размерах, достаточных для частичного погашения ущерба, причиненного ими дорожному хозяйству. Статья 12.34 устанавливает ответственность за несоблюдение требований по обеспечению безопасности дорожного движения при ремонте и содержании дорог, железнодорожных переездов и иных дорожных сооружений, либо за непринятие мер по предотвращению возникновения, а при возникновении - мер по устранению ситуаций, угрожающих безопасности дорожного движения.

Необходимо отметить, что при проведении на дорогах ремонтных работ, достаточно часто наблюдаются ситуации, когда в соответствии с требованиями безопасности устанавливаются соответствующие знаки, ограничивающие скорость движения транспорта, устанавливаются ограждения, заужающие ширину проезжей части, однако ремонтные работы при этом не ведутся что приносит значительный ущерб пользователям дорог.

В связи с этим, предлагается следующее изменение текста статьи: Несоблюдение требований по обеспечению безопасности дорожного движения при ремонте и содержании дорог, железнодорожных переездов и иных дорожных сооружений, либо не принятие мер по своевременному выполнению ремонта ... И далее по тексту.

Второй вариант обеспечения адекватной административно-правовой ответственности предусматривает разработку и включение в Особенную часть КоАП отдельной, самостоятельной главы «Административные правонарушения в области дорожного хозяйства», предусматривающей административную ответственность за правонарушения, допускаемые при осуществлении следующих направлений дорожной деятельности: 
- $\quad$ при оценке состояния автомобильных дорог и дорожных сооружений;

- при выполнении проектно-изыскательских работ;

- при осуществлении строительства, реконструкции, капитального ремонта, ремонта и содержания автомобильных дорог и дорожных сооружений;

- $\quad$ при осуществлении независимого контроля за своевременным, качественным выполнении в полном объеме научно исследовательских работ, работ по проектированию, строительству, реконструкции, капитальному ремонту, ремонту и содержанию автомобильных дорог и дорожных сооружений;

- при исполнении государственными органами возложенных на них полномочий, включая обоснованное планирование, финансирование дорожных работ;

- при обеспечении сохранности автомобильных дорог и дорожных сооружений;

- при обеспечении безопасности ведения дорожных работ;

- при обеспечении соблюдения экологических норм и правил в процессе выполнения дорожных работ.
Предпринятое в рамках настоящей статьи сравнительно-правовое исследование определило проблему совершенствования действующего законодательства в сфере повышения ответственности за правонарушения, допускаемые в области автомобильных дорог и дорожной деятельности как крайне актуальную.

Совершенствование Кодекса Российской Федерации «Об административных правонарушениях», а также Федерального закона «Об автомобильных дорогах и дорожной деятельности..» №257-Ф3 от 8.11.2007 в части касающейся автомобильных дорог и дорожной деятельности, путем включения в них новых норм об ответственности, позволит не только оптимизировать систему ответственности пользователей дорог и организаций, осуществляющих эксплуатацию дорог, но и что принципиально важно - привести в систему ответственность органов управления дорожным хозяйством, а также их руководителей.

Такое решение позволит кардинально изменить всю сложившуюся систему управления дорожным хозяйством и будет способствовать активизации строительства новых автомобильных дорог и приведению существующей дорожной сети в состояние, отвечающее требованиям нормативно-технических документов.

\section{Библиография:}

1. Транспорт России № 4326.11 - 2.12. 2012 г.

2. Дорожное хозяйство России цифры и факты. - М.:Росавтодор, 2011 г. - 279 с.

3. Шумейко А.Н., Юрковский И.Н., М.В. Немчинов Автомобильные дороги России. Состояние и перспектива. - М.: Молодая гвардия, 2007. - 275 с.

4. Отчет «Анализ зарубежного дорожного законодательства». - М.: Росдорнии. - 2003 г. - 270 с.

5. Хеггие И., Вискерс П. Управление и финиансирование автомобильных дорог в рыночных условиях / Перевод под ред. проф. В.В. Сельянова - М.: МАДИ(ТУ), 1999. - 174 с.

\section{References (transliterated):}

1. Transport Rossii № 4326.11 - 2.12. $2012 \mathrm{~g}$.

2. Dorozhnoe khozyaistvo Rossii tsifry i fakty. - M.: Rosavtodor, 2011 g. - 279 s.

3. Shumeiko A.N., Yurkovskii I.N., M.V. Nemchinov Avtomobil'nye dorogi Rossii. Sostoyanie i perspektiva. - M.: Molodaya gvardiya, 2007. - $275 \mathrm{~s}$.

4. Otchet «Analiz zarubezhnogo dorozhnogo zakonodatel'stva». - M.: Rosdornii. - 2003 g. - $270 \mathrm{~s}$.

5. Kheggie I., Viskers P. Upravlenie i finiansirovanie avtomobil'nykh dorog v rynochnykh usloviyakh / Perevod pod red. prof. V.V. Sel'yanova - M.: MADI(TU), 1999. - 174 s. 